\title{
APLIKASI PLC SEBAGAI PENGATUR ARAH PUTARAN MOTOR DC UNTUK MENGGERAKAN PMS PADA MINIATUR GARDU INDUK
}

\author{
Syarif Aripin, Moediyono \\ Program Studi Diploma III Teknik Elektro \\ Fakultas Teknik Universitas Diponegoro
}

\begin{abstract}
Syarif Aripin, Moediyono, in this paper explain that experiment PLC module is a module that consists of modules and visual experiments. This experimental module consists of PLC (Programmeble Logic Controller) which contained PLC in Central Processor Unit (CPU), memory such as RAM (Radom Access Memory), EPROM (Erasable Programmable Only Memory), EEPROM (Electrical Erasable Programmeble Read Only Memory), input-output module and power supply units (Power supply). PLC is used as props in a series of applications to set the dc motor speed desired by mengguanakan input of the switch. OMRON PLC used is CPIEE with $40 \mathrm{I} / \mathrm{O}$, ie 24 inputs and 16 outputs, PLC is used here as a regulator to enable drivers dc motor is used as a regulator dc motor rotation direction to move pms. In the later rounds measured measurement value is varied. The results of these measurements can be read on the voltmeter and ammeter.
\end{abstract}

Keywords: Driver Motor, DC Motor, Omron PLC CP1E, PMS.

\section{PENDAHULUAN}

Pemisah (PMS) atau Disconnecting Switch (DS) adalah suatu peralatan sistem tenaga listrik yang berfungsi sebagai saklar pemisah rangkaian listrik tanpa arus beban (memisahkan peralatan listrik dari peralatan lain yang bertegangan), dimana pembukaan atau penutupan PMS ini hanya dapat dilakukan dalam kondisi tanpa beban. Pemisah terdiri dari Pemisah bus, Pemisah Line dan Pemisah tanah memiliki Pisau atau lengan kontak, dapat dibuka atau ditutup. Pengoperasian Pms disini (membuka /menutup) dengan memutar menggerakkan lengan Pms melalui fasilitas yang digerakan Oleh motor.

\section{LANDASAN TEORI}

Motor DC

Teori dasar dari motor arus searah adalah apabila sebuah kawat berarus diletakkan antara kutub magnet (U-S), maka pada kawat itu akan bekerja suatu gaya yang menggerakkan kawat itu. Motor arus searah adalah suatu mesin yang berfungsi mengubah tenaga listrik arus searah (DC) menjadi tenaga gerak atau putaran dimana tenaga gerak tersebut berupa putaran rotor. Operasi motor tergantung pada interaksi dua medan magnet. Motor listrik bekerja dengan prinsip bahwa dua medan magnet dapat dibuat berinteraksi untuk menghasilkan gerakan. Tujuan motor adalah untuk menghasilkan gaya yang menggerakkan (torsi). Prinsip motor ditunjukkan pada gambar 1.

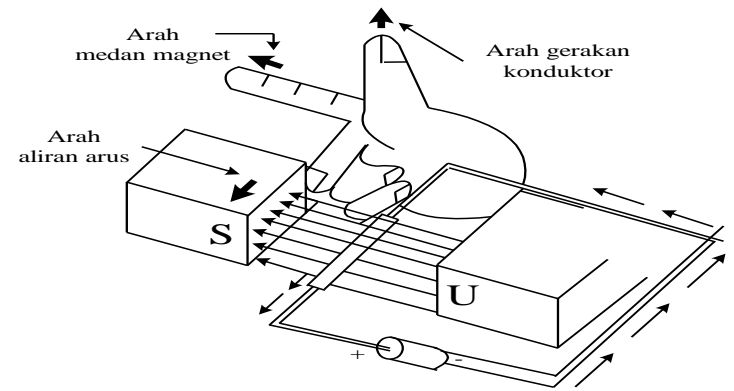

Hukum tangan kanan

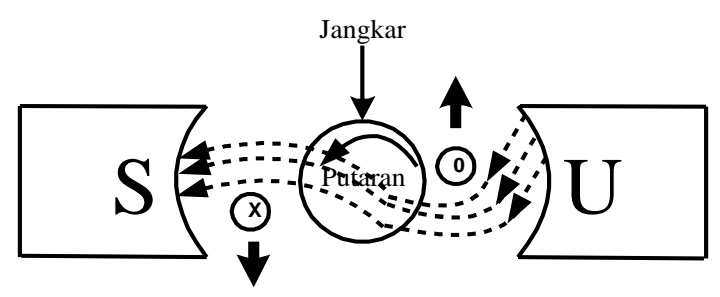

(b) mengembangkan torsi motor

Gambar 1. Prinsip motor

\section{Pengaturan Kecepatan Motor DC}

Motor arus searah dapat digambarkan dengan model seperti pada gambar 2 .

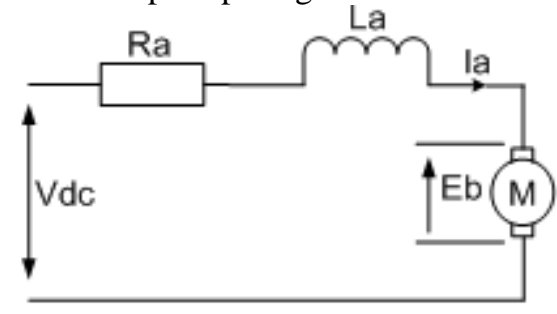

Gambar 2. Model dari motor arus searah 
Secara umum persamaan kecepatan dan torsi untuk motor arus searah adalah sebagai berikut :

$$
\text { Maka : } \quad \omega=\frac{V d c-I a \cdot R a}{K b \phi}
$$

Keterangan :

$\omega=$ Kecepatan motor (rad/detik)

$\mathrm{Eb}=\mathrm{GGL}$ lawan yang dibangkitkan oleh jangkar (Volt)

$\mathrm{Kb}=$ Tetapan kecepatan motor (V/A.rad/det)

$\Phi=$ Fluks per kutub $(\mathrm{Wb})$

Ia $=$ Arus jangkar (Ampere)

$\mathrm{Vdc}=$ Tegangan yang masuk ke motor (Volt)

$\mathrm{Ra}=$ Hambatan pada jangkar $(\mathrm{Ohm})$

Relay

Relay adalah suatu saklar yang memanfaatkan kemagnetan listrik. Keunggulan relay dibandingkan dengan saklar mekanik biasa adalah dapat dipakai dengan aman untuk mengoperasikan peralatan dan mesin-mesin jarak jauh.

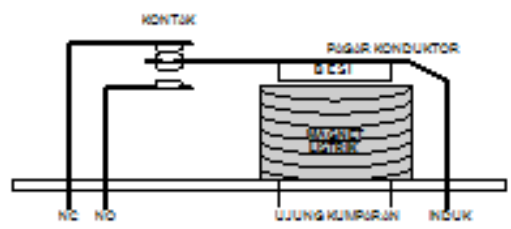

Gambar 3. Relay dua kutub (Bipolar)

\section{Saklar Pembatas (Limit Switch)}

Limit switch atau dalam bahasa Indonesianya bisa juga disebut sensor pembatas, dalam artian mendeteksi gerakan dari suatu mesin sehingga bisa mengontrolnya atau memberhentikan gerakan dari mesin tersebut sehingga dapat membatasi gerakan mesin dan tidak sampai kebablasan.

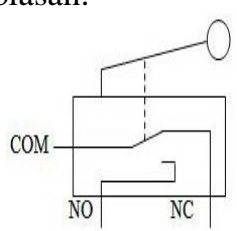

(Kontruksi Limit Switch)

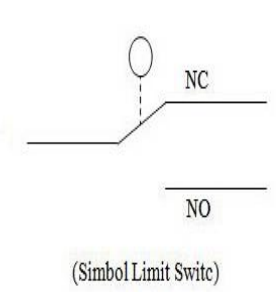

(SimbolLimit Switc)
Gambar 4. Limit switch

\section{Pemisah (PMS)}

Disconnecting switch atau pemisah (PMS) suatu peralatan sistem tenaga listrik yang berfungsi sebagai saklar pemisah rangkaian listrik tanpa arus beban (memisahkan peralatan listrik dari peralatan lain yang bertegangan), dimana pembukaan atau penutupan Pms ini hanya dapat dilakukan dalam kondisi tanpa beban.

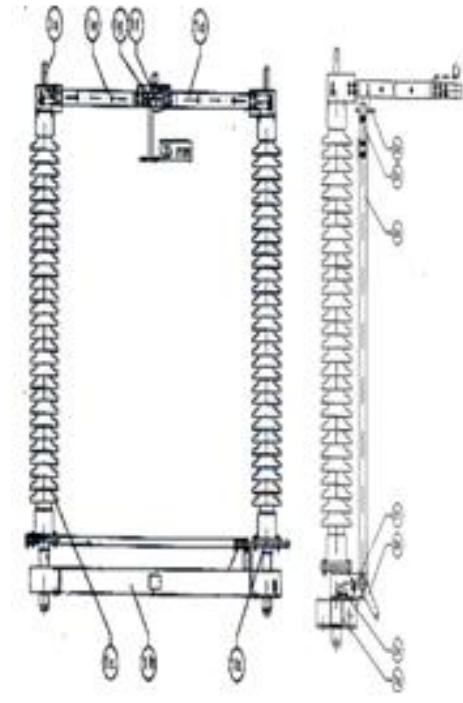

Gambar 5. Pemisah

\section{PRINSIP KERJA ALAT}

Prinsip Kerja Driver Motor DC Sebagai Penggerak PMS.

Prinsip kerja pada rangkaian Arah putar motor DC Sebagai penggerak PMS ini mendapat masukan dari 4 alamat output PLC yang telah dibagi. Berikut ini adalah gambar rangkaian driver motor DC secara keseluruhan.

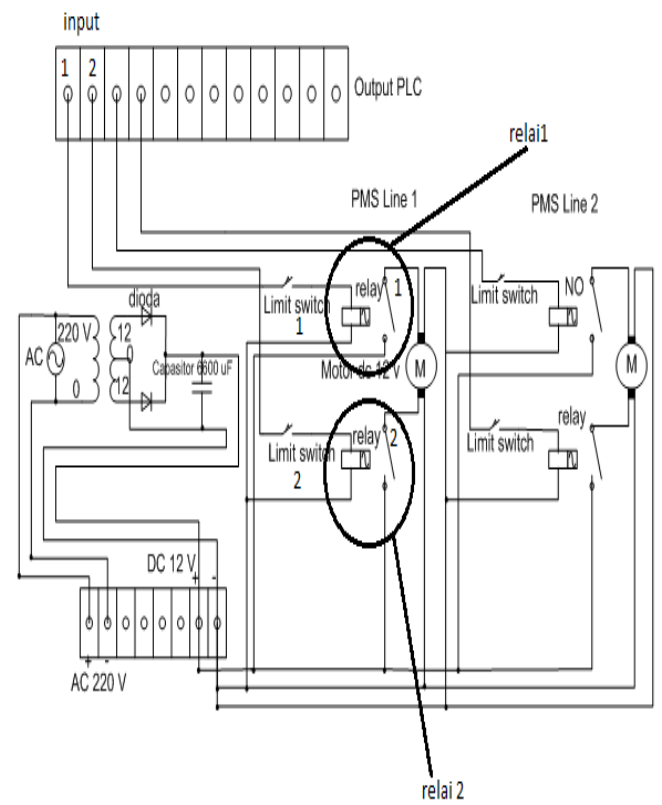

Gambar 6. Rangkaian Driver Motor DC Sebagai penggerak PMS.

Dari Rangkaian di atas mempunyai fungsi sebagai pengatur putaran motor DC menjadi searah jarum jam dan berlawanan jarum jam. Gambar diatas menunjukkan terdapat 2 driver untuk PMS Line 1 maupun PMS Line 2. Namun, fungsi dari 
driver PMS Line 1 dan PMS Line 2 sama karena hanya untuk mengatur arah putaran motor DC.

\section{Putaran Motor Searah Jarum Jam (CW)}

Dari rangkaian driver diatas untuk memutar motor searah jarum jam adalah ketika input 1 diON kan maka relay 1 akan ON, yang mengakibatkan polaritas tegangan pada Relai 1 menjadi Positif. Sedangkan pada relay 2 karena dalam kondisi OFF maka polaritasnya negative. Hal ini mengakibatkan motor akan berputar searah jarum jam (CW). Putaran motor akan berhenti ketika Limit Switch 2 tertekan dan limit switch 1 terlepas. Sehingga PMS akan membuka

\section{Putaran Motor Berlawanan Jarum Jam (CCW)}

Ketika kondisi motor berputar berlawanan jarum jam maka limit switch 2 pada kondisi tertekan dan input 2 pada posisi di-ON kan. Arus akan mengalir menuju relay 2 sehingga relay 2 pada kondisi -ON. Sedangkan kondisi Relay 1 adalah $\mathrm{OFF}$, dari kondisi tersebut.

\section{PERCOBAAN DAN PENGUKURAN}

Pengukuran Motor DC Pada Saat Proses BukaTutup Pms

- Menghubungkan tegangan 220 V AC pada rangkaian

- Menghubungkan catu daya 12 VDC pada motor DC melalui output PLC

- Menjalankan program motor DC.

- Mengukur tegangan pada saat motor berputar Searah jarum jam dan berlawanan jarum jam

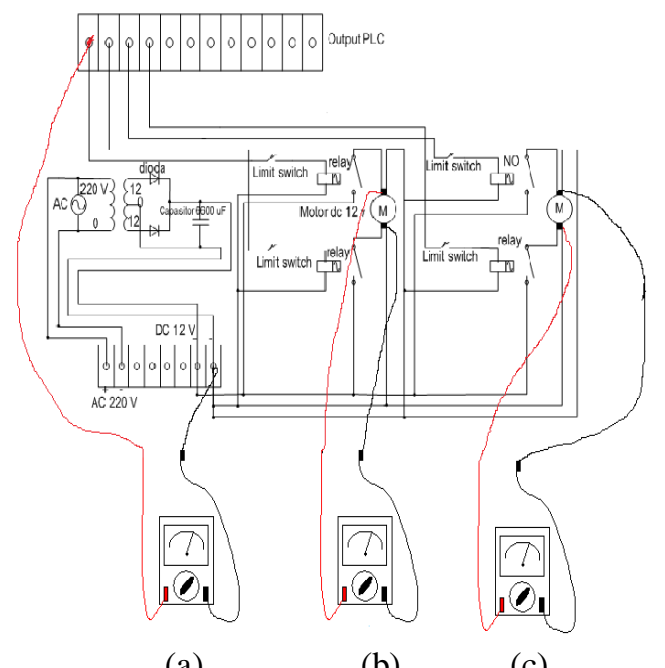

(a)

(b)

(c)

Gambar 7. Titik-titik pengukuran Motor Saat bergerak searah jarum jam dan berlawanan jarum jam

\section{Pengukuran Motor DC Pada Saat Pms (Pemisah) Menutup}

Terminal input PLC yang digunakan pada alat ini hanya 3 buah alamat yaitu 00000, 00001, dan 00002. Digunakan untuk men-start program.Pengukuran tegangan dilakukan pada saat terminal input mendapat sinyal maupun saat tidak mendapat sinyal dari saklar input. Berikut ini adalah tabel-tabel hasil pengukuranya.

Tabel 1. Pengukuran tegangan motor pada saat menutup / berlawanan arah jarum jam

\begin{tabular}{ccc}
\hline $\begin{array}{c}\text { Alamat } \\
\text { output }\end{array}$ & Instruksi & $\begin{array}{c}\text { Tegangan } \\
\text { sinyal }\end{array}$ \\
\hline 00000 & Start program & 14 V DC \\
10000 & Motor PMS Line 1 & 14 V DC \\
10001 & Motor PMS Line 2 & 13,8 V DC \\
10002 & Motor PMS Bus 1 & 13,8 V DC \\
10003 & Motor PMS Bus 2 & 13,8 V DC \\
\hline
\end{tabular}

Pada saat motor bergerak kedua line berjalan menutup bersamaan mulai dari Close PMS Line, Close PMS Bus.

\section{Pengukuran Motor DC Pada Saat Pms (Pemisah) Membuka}

Terminal input PLC yang digunakan pada alat ini hanya 3 buah alamat yaitu 00000, 00001, dan 00002. Digunakan untuk men-start program.Pengukuran tegangan dilakukan pada saat terminal input mendapat sinyal maupun saat tidak mendapat sinyal dari saklar input. Berikut ini adalah tabel-tabel hasil pengukuranya.

Tabel 2. Pengukuran Tegangan motor pada saat membuka / Searah jarum jam

\begin{tabular}{ccc}
\hline Alamat & Instruksi & Tegangan sinyal \\
\hline 00000 & Start program & 14 V DC \\
10105 & Motor PMS Line 1 & 14 V DC \\
10104 & Motor PMS Line 2 & 14 V DC \\
10103 & Motor PMS Bus 1 & 13,8 V DC \\
10102 & Motor PMS Bus 2 & 14 V DC \\
\hline
\end{tabular}

Pada saat motor bergerak kedua line berjalan membuka bersamaan mulai dari Open PMS Line, Open PMS Bus.

\section{KESIMPULAN}

Dari Aplikasi PLC Sebagai Pengatur Arah Putaran Motor DC Untuk Menggerakan PMS Pada Miniatur Gardu Induk ini dapat di ambil kesimpulan sebagai berikut :

- Pada Miniatur Gardu Induk ini PMS (Pemisah) digerakan Oleh Motor DC. Motor ini nantinya akan menggerakan PMS line Untuk membuka ke atas dan menutup kebawah, Serta membuka dan menutup PMS Bus kekanan dan kekiri. 
- Untuk mengendalikan putaran motor dc Searah jarum jam dan berlawanan arah jarum jam digunakan PLC Omron CP1E.

- Didalam Aplikasi PLC Sebagai Pengatur Arah Putaran Motor DC Untuk Menggerakan PMS Pada Miniatur Gardu Induk, PLC Omron CP1EE 40 DRA diprogram sehingga dengan sinyal dari saklar input dapat mengatur Arah putaran motor DC untuk Menggerakan PMS.

- Untuk Membatasi gerakan atau memperhentikan motor DC agar tidak kebablasan menggunakan sensor Limit Switch

\section{DAFTAR PUSTAKA}

1. Malvino, A.P.. 1996. Prinsip-prinsip Elektronika (terjemahan Hanapi Gunawan). Erlangga: Jakarta.

2. OMRON, 2002, Operation Manual Mini HType PCs : C 20H, C28H, C $40 \mathrm{H}$ and C 60H Programmable Controller, Omron Indonesia.

3. OMRON, 1999, CPM 1A Programmable Controller : Operation Manual.

4. Sulistyo, Agus. 2005._Aplikasi PLC Sebagai Pengatur Arah putaran Motor Stepper Dengan Indikator Lampu 220 VAC dan Buzzer Menggunakan Programming Console, Semarang : Universitas Diponegoro

5. Sumisjokartono, 1997, Elektronika Praktis, PT. Elektronika Komputindo kelompok Gramedia.
6. Suryatmo, 1996, Dasar-dasar Teknik Listrik, PT Rineka Cipta, Jakarta.

7. Tim Jasa Pendidikan Dan Pelatihan PT. PLN (Persero). 2008. Peralatan GI. PT. PLN (Persero) : Jakarta.

8. Tim Jasa Pendidikan Dan Pelatihan PT. PLN (Persero). 2008. Pengoperasian SOP GI dan Manuver GI. PT. PLN (Persero) : Jakarta.

9. Tim Penyusun. 2009. Buku Petunjuk Batasan Operasi dan Pemeliharaan Peralatan Penyaluran Tenaga Listrik : Pemisah (PMS) No. Dokumen : 8 22/HARLUR-PST/2009. Jakarta : PT PLN (Persero).

10. Tobing, L. Bonggas. 2003. Peralatan Tegangan Tinggi. Jakarta : Gramedia Pustaka Utama.

11. Wasito, 1995. Vademekum Elektronika. Jakarta : Gramedia.

12. Yudiono KS. 1984. Bahasa Indonesia Untuk Penulisan Ilmiah. Semarang, Universitas Diponegoro Semarang

13. Yonez. Kontaktor. (online).(http://yonezelectrical.blogspot.com/2012/01kontaktor , diakses tanggal 28 Mei 2012);18.43

14. Zamroni, Muhammad. 2010.. Kendali Motor DC Sebagai Penggerak Mekanik Pada Bracket LCD Proyektor Dan Layar Dinding Berbasis Mikrokontroller AT89s51, Semarang: Universitas Diponegoro. 